\title{
The Teaching of Zoology. A Study of the Concepts of Students of Youth and Adult Education
}

\author{
Simone Paixão Araújo Pereira ${ }^{1}$, Maria Helena da Silva Carneiro ${ }^{2}$ \\ ${ }^{1}$ Federal Institute of Goias, Luziânia, Brazil \\ ${ }^{2}$ University of Brasília, Brasília, Brazil \\ Email: simonepaixao@ifg.edu.br
}

Received October $28^{\text {th }}$, 2013; revised November $28^{\text {th }}$, 2013; accepted December $5^{\text {th }}, 2013$

\begin{abstract}
Copyright @ 2014 Simone Paixão Araújo Pereira, Maria Helena da Silva Carneiro. This is an open access article distributed under the Creative Commons Attribution License, which permits unrestricted use, distribution, and reproduction in any medium, provided the original work is properly cited. In accordance of the Creative Commons Attribution License all Copyrights (c) 2014 are reserved for SCIRP and the owner of the intellectual property Simone Paixão Araújo Pereira, Maria Helena da Silva Carneiro. All Copyright @ 2014 are guarded by law and by SCIRP as a guardian.
\end{abstract}

This work is a study of previous conceptions of young students and adults about the content relating to zoology, in particular insects. We emphasize that the knowledge built by these students should be respected and considered as an important variable in the process of teaching and learning of scientific and technological knowledge. To explain the students' prior knowledge on the subject in question, we developed a questionnaire consisting of three themes relating to animals: the general concept, the characterization of invertebrates and the relationships established between insects and man. The data analysis allows us to state that although the vast majority of students evidence the role that insects play in the ecological balance, they still use common sense criteria to characterize them at the expense of biological criteria. Our studies show that the initial representations made by students about the concept of animal and, particularly, insects showed once again the need to propose teaching activities that facilitate the conceptual change from the confrontation of ideas and these students with scientific knowledge.

Keywords: Education of Youth and Adults; Teaching Science; Conceptions; Insects

\section{Introduction}

The education of youth and adult comprises a shaft which is permeated by literacy reaching the university, covering diverse educational proposals. According to Haddad and Di Pierro (2000), the education of youth and adults always comprised a very diverse set of processes and formal and informal practices related to the acquisition or expansion of basic knowledge, technical and professional skills or socio-cultural abilities.

The adult and youth who participate in education constitute a heterogeneous group with regard to social, cultural, economic, and the diversity of age, but form a unified group by seeking recognition of their citizenship through the formalization of the educational process.

"The adult in the education of youth and adults is not the college student, the qualified professional who attends continuing education courses or specialization, or adult interested in improving their knowledge in areas such as arts, foreign languages or music, for example. [...] And the young, embedded in the territory of the former adult education relatively recently, is not that one with a history of regular schooling, the preppy or student extracurricular courses in pursuit of personal enrichment. [...] As previously described adult, he is also an outcast of the school, but generally incorporated into supplementary courses in earlier stages of education, with higher chances thus completing primary school or even middle school.” (Oliveira, 1999: p. 59).
The author portrays a broad reality that includes the profile of most students' education of youth and adults, as they choose this mode of teaching to finish basic education, which for various reasons did not complete at the regular age. Expanding and supporting the ideas of the authors mentioned above, Paiva (2006) understands for adult education the totality of organized educational processes, whatever the content, the level or the method, whether formal or non-formal, that prolong or replace the initial education offered in schools and universities, and in the form of professional learning, linked essentially concerned with the idea of development.

Reflecting on the education of youth and adults, Freire (2001) asserts that the concept goes, moving in the direction of popular education as the reality begins to make some demands to sensitivity and scientific competence of teachers and educators, understanding it broader. He further states that the education of young people and adults has a great importance on encouraging us to put into practice according to our possibilities, an education through labor, which encourages collaboration and not competition, which values mutual aid and not individualism, to develop critical thinking and creativity, and not passivity. An education which is based between the theory and practice, between intellectual and manual labor and, therefore, encourages students to think right. Understanding for thinking right as a requirement that the moments of the gnosiological cycle putting the curiosity, becoming more and more methodically rigorous, transits from the ingenuity to what is called "epistemological 
curiosity". The concept of Adult Education goes, moving in the direction of popular education as the reality begins to make some demands to sensitivity and scientific competence of teachers and educators. One of these requirements has to do with a critical understanding of the educators of what is happening in the everydayness of the popular medium (Freire, 2001).

Welcoming Oliveira (1999) is in the belief that these students have a different reintegration into the school context for coming from a fragmented history of schooling; Paiva (2006) considers the very wide range of modalities and corroborating Freire (2001) advocates a emancipatory education for the fullness of man in the world. They understand that the education of youth and adults covers a group of individuals who for various reasons at some point stopped attending school regularly and redeeming their rights as citizens by seeking the path of formal education to break with the processes of exclusion which were victimized. And in the process their knowledge constructed must be respected and considered as an important variable in the process of teaching and learning of scientific and technological knowledge. These individuals at a particular time of their life history were removed from regular education by an imperative necessity of surviving or because they did not identify with the models adopted by the formal education, they did not feel included in the process or not recognized the meaning of the them for their lives return to the school environment and face a reality that for different reasons does not change to receive them, despite documents ensuring their access. In the process, construction of their knowledge must be respected and considered as an important variable in the process of teaching and learning of scientific and technological knowledge and stay in school.

\section{Teaching Science and Biology and Relation of Insects in Adult World}

In recent years, the organization of science teaching has suffered many proposals for transformation. In general, the changes presented are intended to improve the conditions of formation of the scientific spirit of the students considering the historical-cultural circumstances of society. The changes attempt to situate the science and its teaching in time and space, emphasizing each time an aspect considered more relevant in the way humans understand and act scientifically in the world through knowledge, in general, different from common sense.

The school today is strongly committed to quality education and encourages responsible citizenship. School content taught to students are understood as part of an instrumental need for everyone to understand the reality around them and acquire the necessary conditions to discuss, debate, opine and even intervene in social issues that mark the historical moment. However, in some situations the teaching of science has limited itself to a process of memorizing words, classification systems and formulas through teaching strategies in which students learn scientific terms, but not construct meaning. With a view of science as something absolutely true and finished, students will have difficulty accepting the possibility of two or more alternatives to solve a particular problem. Presenting the provisional nature of scientific theories and uncertain allows students to evaluate the applications of science, taking into account the opinions of experts disputed.

In our daily lives, we have access to several information related to scientific knowledge, and sometimes conflicting opi- nions are issued about the same phenomenon. If we do not provide to the student the opportunity to monitor and minimally mastering scientific knowledge, he could become hostage to their own lack of knowledge. The teaching of science to promote science and technology education of citizens, and helping students to build knowledge, skills and values necessary to make responsible decisions on matters of science and technology in society and act in resolving such issues. This process shall promote understanding of science as a human activity and not simply as neutral activity distant social problems.

The teaching of science in classes consisting of youth and adults tend to reproduce the same pedagogical practices applied in regular classes. Each learner, young or adult, has its own way of learning, and these are often associated with learning experience of adult life. Learning (in its broadest sense) is the key to the process of development of the individual and consolidated the extent that it can transform your experience and reframe their experiences and not simply accumulate knowledge. Each one develops from their own experiences a vast repertoire of knowledge about objects, people, phenomena, and use this knowledge to achieve their goals because of significant processes related to their personal or professional life, promotes autonomy. The concept of autonomy is full of meaning and refers to the idea of individual development; however the knowledge and skills are social products. Social interactions nurture reflection on the initial knowledge on the part of the student, and the formal education a focus for reorganization of these conceptions and construction of new knowledge.

\section{Why Study the Designs Built by Students about Insects?}

Studies taken in contexts different from ours showed that adults construct representations of insects closer to affective characteristics, hardly using scientific criteria to identify them. Costa Neto and Carvalho (2000) researching undergraduate students from the State University of Feira de Santana, Bahia, reported that construction of ethno category "insect" became second ambiguous perceptions, once asked the students demonstrated both reactions of fear, disgust and contempt bodies included in the field ethno zoological "insect", as they attributed ecological functions, aesthetic and utilitarian. In a study on the medicinal use of animals recognized as "insects" by market traders of the Center for Supply Feira de Santana in Bahia, Costa Neto and Resende (2004), claim that popularly the "insects” include other animals that do not belong to the class Insecta, like spiders, snakes and rats. These authors showed that these animals are usually considered disgusting, noxious, dangerous, or that may cause harm to human health. However, some species of the class Insecta can receive a rating ethnobiological different, because they have a positive perception within the society in question. Subsequently Lima et al. (2010) presented results of a study on the perception of a community in the interior of Pernambuco about bugs. In this study most often cited by residents were cockroaches, flies and ants, and $57.8 \%$ of women showed a sense of disgust and fear in relation to insects, which corroborates with the cultural perception of insects in our daily lives. These works have strengthened our choice to adopt this theme as an object of study, considering that this scientific concept approached from the initial remains strongly characterized by affective aspects in the adult population. We expected that the criteria related to the identification 
of the group of insects were different; they were closer to the current scientific knowledge, due to its inclusion in science education from elementary school to high school.

However, these animals play an important ecological role because they act as pollinators, herbivores, decomposers, predators and parasitoids. Furthermore, the insects caused and are causing some impact in human cultures for its almost infinite variety of colors, shapes, sizes, lifestyles and also the sounds they produce (Costa Neto, 2000). Their cultural influence can be felt in literature, language, music, and graphic arts, cinema, theater, cooking, medicine, history representative, religion and recreation of the different societies, both past as contemporary (Costa Neto, 2007). These animals bring contribution to ecological control, as they are primarily responsible for the spread of pollen grains, considered the greatest pollinators on the planet that exist in a relationship of mutuality, as they feed on nectar and other substances present in the plant in return pollen adheres it is the animal that spreads to visit another plant.

\section{Theoretical Aspects}

The pedagogical constructivism proposes that the student participates actively in his/her own learning process through experimentation, research group, the stimulus to the development of the doubt and reasoning, among other procedures.

In a reflection on the influence of constructivism in teaching contemporary science, Mathews (2000) identifies three main traditions of constructivism: the educational constructivism, the philosophical constructivism and the sociological constructivism. In the educational constructivism in him highlights a literature review identified seventeen variants of constructivism, namely: contextual, dialectical, empirical, information processing, methodological, moderate, Piagetian, post-epistemological, pragmatic, radical, realistic and socio-historical, among others. To the author the constructivism has served to the teaching of science and mathematics to emphasize, once again, the importance of students' prior knowledge and their resistance to change even after the teaching process. Within this approach the student must take an active role in the learning process and their prior knowledge substantiates the teaching process and the definition of a body of knowledge.

From the 70s, was observed between researchers in science education a major commitment to study more deeply the ideas that students bring to the classroom. Posner, Strike, Hewson, \& Gertzog (1982) stressed the need for a theoretical model that would describe or explain the substantive dimensions of the process by which the ideas and content of students' conceptions change in interaction or impact with new ideas, new information, content and evidence. From this perspective, learning is seen as rational and investigative activity, defined by the occurrence of changes, substitutions, not necessarily abrupt. According to Posner et al. (1982), these central concepts are not judged in terms of some immediate capacity to generate correct predictions. Before, such central concepts are evaluated in terms of the capacity that they claim to solve current problems. When these concepts generate classes of problems for which they are incapable of sustaining resolution, no change or substitution by alternative conceptions that demonstrate the potential to address the problems posed by previous central concepts, and these concepts are shown capable of generating prominent lines of investigation. Thus, learning is conceived as a process of conceptual change. These authors based on the perspectives of science and philosophy of Kuhn's science worked with analogies between changes in the evolution of scientific thought and changing conceptions of the student. We believe that research and learning occur in the context of current concepts of students. Whenever the student is a new phenomenon, it must rely on their current concepts for organizing your research. Without such concepts is impossible for the student to ask a question about the phenomenon, to know what would count as an answer to question, or to distinguish relevant from irrelevant characteristics of the phenomenon (Posner et al., 1982).

For these authors the initial representations of the students are the foundation for the teacher to organize their pedagogical work. In their study the authors clarify that sometimes, students use existing concepts to deal with new phenomena, for this phase of conceptual change use the term assimilation. Often, however, the current concepts of the students are not sufficient to enable them to understand a new phenomenon successfully. In these cases, the student must replace or reorganize its central concepts; this more radical form of conceptual change was called accommodation. In this proposal, even in a large conceptual reorganization, however, not all the concepts are replaced. Individuals will retain many of their current concepts, some of which function to guide the process of conceptual change. Posner et al. (1982) proposed that for a subject change your mind it is necessary to first try some dissatisfaction with current ideas, and that the new design is intelligible, that is, accompanied by coherent representations in the form of propositions and/or images; plausible this is able to solve known anomalies, and consistent with other knowledge of the student; fertile, this is capable of solving the problems of the student and lead to new discoveries. The process of conceptual changes unfolds in the backdrop of existing concepts for the individual.

In this perspective, the teacher should propose pedagogical situations that enable cognitive conflict so that students feel the need to revise their representations. Strategies for conceptual change are based, therefore, a kind of "manipulation" of learning situations by the teacher in order to arouse students from unsuccessful attempts to assimilate a new experience or design in their conceptual ecology, the decision to accommodate scientific knowledge, even at the expense of their previous ideas (El-Hani \& Vicenzo Bizzo, 2002). For these authors strategies for conceptual change should be planned from teaching strategies that enable explicit or produce anomalies between the initial representations and experiences of the learner, should arouse dissatisfaction with these representations and enable thus that scientific knowledge is addressed in an advantageous position to solve the problem at issue.

Based these assumptions, we chose to identify and analyze the knowledge constructed by students about insects, as we intend, in the context of our master thesis, proposing a series of learning activities that allows students to reflect on the insects' representations.

\section{Methodological Aspects}

This study aimed to identify and interpret the information about insects of the students of the second semester of High School of the Integration Program of Professional Education in Basic Education in Youth and Adult mode-PROEJA. To explain the students' prior knowledge about the topic in question, we prepared a questionnaire (Annex 1) consisting of three themes related to animals: the general concept, the characteri- 
zation of invertebrates and the relationships that are established between insects and man. Study participants attending a class of Biology (Youth and Adults) consisting of twenty-three (23) students. These were selected students who participated in all the activities proposed for this sequence of teaching. Therefore, it is not a probability sample. The analysis included the questionnaires applied to eleven (11) students. The analysis of the responses was made from successive readings, which supported the definition of the categories.

\section{Analysis and Discussion of Data}

Insects are animals extremely successful and are associated with various aspects of human's life. Whether for its large number of species in different environments, or their importance as pollinators, natural enemies of agricultural pests, food, disease vectors, agricultural and urban pests, insects are in constant interaction with humans. Justified at this juncture we analyze the data presented in the questionnaires answered by the students.

Initially students were asked to write the name of ten animals. By analyzing the response of this question was possible to identify a reduced role of insects in the group of animals, which leads us to build the hypothesis that for most students this group of arthropods belong to another category of living beings.

In a second question students should explain the characteristics that distinguish animals from other living beings. Relate to the characteristics of the 05 animals (five) students established as criteria for characterization only affective relations they had with the animals in these cases used features such as "loyalty", "treacherous", “subtle”, “friend”, “friendly”, “determined”, "docile". In this issue three (03) students in guided affective characteristics and biological cited terms such as "domestic", "mammal”, “employee”, “vertebrate”, “quadruped”, "very easy to learn". The description and characterization guided exclusively on biological characters were drawn by three (03) students who used terms like " carnivore”, "vertebrate”, "invertebrate”, "got by”, “claws”, "feathers”, "scales”, "hull”. These results show that most of the answers the parameters scientifically accepted at the time were not assigned to the animals, which highlights the need to propose learning activities that allow students to reflect on the criteria used to distinguish an animal from other living beings.

In the question which asked the characterization of invertebrate animals, six (06) students described invertebrates basing on the inharmonious relations of which participated invertebrates using terms such as " hostile and harmful" and features such as "soft-bodied”, "boneless", "fragile”, "keeper with power of locomotion". In a question, it was presented the statement "Insects are beings that cause damage to health and are related to the transmission of diseases". Students should express the degree of agreement with the statement and justify its position, in this case 'answers on a scale of agreement, drawn up in order to reveal the relations established between the student and adult insects, seven (07) students agree that insects are beings that cause damage to health and are related to disease transmission and highlighted aspects related to diseases such as dengue and Chagas's disease and the presence of flies as carriers of pathogens. In the following question stated that "If there was the elimination of insects in homes the health of the population would greatly improve". And we asked the students to express their degree of agreement, and in this context eight (08) stu- dents expressed their agreement with this proposition. The last point addressed in the questionnaire was the proposition of a problem situation in which students should imagine what would happen to the planet if all insects were extinct. Among the 11 study participants eight (08) said that there would be an imbalance in the food chain, which shows that students recognize the ecological value of this group of animals. These responses highlighted the importance of insects to plants and other animals which they relate with in the food chain. So the findings show that students engage in contradiction to characterize the relationships established by the insects. It is important to say that these students made use of other important concepts such as food web to explain the ecological imbalance. The three other students considered the extinction of the insects would be an advantage for the human health.

Based on these results we were sensitized to perceptions that these students establish in relation to invertebrates, especially the insects in their everyday lives and how much to the fact describe the characteristics of this group of superficially addressing predominantly affective aspects at the expense of the biological characterization of animals.

\section{Final Considerations}

Despite the singularities involved in teaching a class of young and adults and the pedagogical propose targeted for this type of education is guided in a homogenization thereof, remains the practice of regular education which does not distinguish the specifics of the individual, and uniform them by forming a group simply called "no-kids" and this is the characteristic that gather them together. The educating "non-child" carries a life story that enriches their activities in school and should be valued as a starting point for the teaching job. The heterogeneity of classes should be seen as a strong promoter of meaningful activities and enable interaction with the cultural differences that provide a construction of knowledge linked to the world of work and social diversity. We understand that the school experience is not a complement of knowledge, but rather an appropriation of knowledge historically produced by mankind that allow them to reach more complex levels of conceptual elaboration. Thus the process of teaching provides the adult learner the awareness of his actions in a planned and deliberate way, to become protagonists of their decisions on the scientific and technological issues.

Data analysis allows us to assert that although the majority of students evidencing the role that insects play in ecological balance, students still use common sense criteria to characterize them at the expense of biological criteria. We believe that these initial representations made by students show, once again, the need to propose educational activities that enable conceptual change. These results will support the organization of educational activities that will be performed and analyzed during biology classes. It is therefore a practical theoretical study which will be developed in the context of my dissertation which still in development.

\section{REFERENCES}

Almeida, A. V. (2007). Insetos brasileiros comentados pelos cronistas coloniais: Séculos XVI e XVII. Sitientibus Série Ciências Biológicas, 7, 113-124.

El-Hani, C. N, \& Vicenzo Bizzo, N. M. (2002). Forms of constructive- 
ism: Conceptual change and contextual constructivism. Ensaio Pesquisa em Educação em Ciências, 4, 37-58.

Costa Neto, E. M., \& Magalhães, H. F. (2007). The ethnocategory "insect” in the conception of the inhabitants of Tapera County, São Gonçalo dos Campos, Bahia, Brazil. Anais da Academia Brasileira de Ciências, 79, 239-249.

http://dx.doi.org/10.1590/S0001-37652007000200007

Costa Neto, E. M., \& Resende, J. (2004). The perception of animals as "insects" and their use as medicinal resources in the city of Feira de Santana, Bahia, Brazil. Acta Scientiarum, 26, 143-149.

Costa Neto, E. M., \& de Carvalho, P. D. (2000). Perception of insects by undergraduates at the State University of Feira de Santana, Bahia, Brazil. Acta Scientiarum, 22, 423-428.

Posner, G., Strike, K., Hewson, P., \& Gertzog, W. (1982). Accommodation of a scientific conception: Toward a theory of conceptual change. Science Education, 66, 211-227. http://dx.doi.org/10.1002/sce.3730660207

Paiva, J. (2006). Plotting concepts and directions for reaffirm the right to education of youth and adults. Revista Brasileira de Educação, 11, 519-539.

Oliveira, M. K. (1999). Youth and adults as subjects of knowledge and learning. Revista Brasileira de Educação, 12, 59-73.

Lima, M. L. O., Lima, V. H. M., Albuquerque, M. F., Silva, A. P., Lira, J. A. M., \& Silva, R. A. (2010). Perception of animals as "insects” by the residents of the village of Nazareth, Cabo de Santo Agostinho, Pernambuco. X Jornada de Ensino, Pesquisa e Extensão, Jepex, 1822 October 2010, Recife: UFRPE.

Freire, P. (2001). Politics and education (5th ed.). São Paulo: Editora Cortez.

Haddad, S., \& Di Pierro, M. C. (2000). Education of youth and adults. Revista Brasileira de Educação, 14, 108-130.

\section{Annex 1}

\section{QUESTIONNAIRE}

Name: Age:

Technician Course: Period:

1 - Give the names of five animals that you know.

2 - Identify at least five characteristics of an animal.

3 - How would you explain to a friend the characteristics of invertebrates?

4 - Classify the following living things into groups: spider, lion, horse, dog, rabbit, butterfly, fly, zebra, elephant, dragonfly, giraffe, mouse, cat, bee, snake, monkey, grasshopper, wolf, jaguar scorpion.

5 - Select the alternative that best expresses your position relative to each statement and discuss the sentences:

Insects are beings that cause damage to health and are related to disease transmission.
( ) STRONGLY AGREE
( ) I AGREE
( ) UNDECIDED
() DISAGREE
( ) STRONGLY DISAGREE
COMMENT:

If there were elimination of insects in homes population health would greatly improve.
( ) STRONGLY AGREE
( ) I AGREE
( ) UNDECIDED
( ) DISAGREE
( ) STRONGLY DISAGREE
COMMENT:

6 - If all insects were removed from the planet, what do you think would happen? 